\title{
Influence factors of depression in elderly patients with chronic diseases.
}

\author{
Ping Wu ${ }^{1,2 \#}$, Liang Li ${ }^{3 \#}$, Weijia Sun ${ }^{4 *}$ \\ ${ }^{1}$ Department of Social Medicine and Health Management, Xiangya School of Public Health, Central South University, \\ Changsha, Hunan Province, PR China \\ ${ }^{2}$ Department of Medical Services, Peace Hospital of Changzhi Medical College, Changzhi, Shanxi Province, PR China \\ ${ }^{3}$ Department of Medical Services, Xiangya Hospital, Central South University, Changsha, Hunan Province, PR China \\ ${ }^{4}$ Department of General Surgery, Xiangya Hospital, Central South University, Changsha, Hunan Province, PR China
}

\#These authors contributed equally to this work

\begin{abstract}
Background: Patients with chronic diseases were often accompanied by negative psychological barriers. We conducted a survey of depression among chronic disease patients to investigate the overall prevalence of depression and related factors of depression.

Methods: 450 patients who were from our hospital from October 2016 to May 2017 were enrolled. A standard questionnaire was used to collect the following information: demographic characteristics and history of diseases. We assessed the depression status and quality of life of study subjects by using scales. Logistic regression was used to analyse the risk factors of depression.

Results: The prevalence of depression was $31.8 \%$. The univariate analysis found that there were no significant differences in depression prevalence between female and male and age group $(P>0.05)$. People with low educational level, more number of disease, from rural area, severe burden of diseases and less social support tend to have higher depression prevalence $(P=0.000,0.007,0.001,0.004,0.006)$. The scores of social and role function and global health in the depression group were higher than that in the control group $(P=0.000)$. The number of disease (Odds Ratio $(\mathrm{OR})$ : 2.67), burden of disease (2.35 for severe), and social support $(\mathrm{OR}=\mathbf{0 . 6 8})$ were independently associated with depression in elderly patients with chronic disease.

Conclusion: The overall incidence of depression disorders for elderly patients with chronic diseases is slightly higher. The clinical staff should pay more attention to the patients of lower education level, poor health care in rural areas and patients with severe burden disease and less social support.
\end{abstract}

Keywords: Depression, Chronic disease, Risk factor, Case-control.

Accepted on November 29, 2017

\section{Introduction}

Currently, chronic disease is a major public health problem with the characteristics of long incubation period, hidden incidence and difficult healing or curing [1]. With the development of the medical technology, medical model changes from the "biomedical mode" to "biology-psychologysocial medical model". It was found that the patients with chronic diseases were often accompanied by negative psychological barriers. Depression and anxiety are the most common negative psychological barriers [2,3]. Importance has been attached to the quality of life after the disease. Mental disorders are very common in patients with chronic disease; and depression and anxiety disorders are most common, which affect the quality of life of patients [4]; Moreover, it is also one of the high-risk factors for cardiovascular adverse events [5].
Depression and anxiety disorders can trigger and aggravate the body's inflammatory response and elevate the level of inflammatory cytokines such as high sensitivity C-reactive protein (hs-CRP) [6,7]. The hs-CRP is a recognized predictor of some chronic diseases, and also the most powerful predictor of major adverse cardiovascular events. Patients are more likely to suffer from depression and anxiety disorders, which reinforce and influences chronic disease in return, forming a vicious cycle, and seriously affecting the prognosis and outcomes of the disease. So we conducted a survey among chronic disease patients in our hospital to investigate the overall prevalence of depression, and related factors of depression, relationship between chronic disease-related depression and quality of life, with the aim of providing theoretical and practical basis for the treatment of elderly patients with depression. 


\section{Materials and Methods}

\section{Study population}

We enrolled our study population who saw their doctor in our hospital from October 2016 to May 2017. The study population have to meet the following criteria: (1) Patients have been diagnosed with one of the following or several of diseases: hypertension, diabetes mellitus, Coronary heart disease, myocardial infarction, chronic hepatitis, liver cirrhosis, diabetes mellitus and chronic renal insufficiency, chronic obstructive pulmonary disease, tuberculosis, mental disease, lupus erythematosus, rheumatoid arthritis. (2) Patients who was 65 y old or more. (3) No history of mental cognitive impairment and alcohol and drug dependence. (4) Survival time was more than three months. (5) No barriers in language communication and can finish the investigation. (6) Patients who experienced severe life stress events within two weeks and or took psychotropic medications were excluded.

\section{Data collection}

A standard questionnaire was used to collect the following information: demographic characteristics, disease information (types, status of disease, treatment). We assessed the depression status of each subject by using Self-Rating Depression Scale (SDS). This scale consisted of twenty items, each item included four options, and each option means one, two, three and four points. The sum of each point was calculated: 53-62 for slight, 63-72 for medium, $>72$ for severe [8].

We assessed the quality of life by using the quality of life questionnaire. This questionnaire consisted of 15 domains with 30 items: function, symptom, quality of life and single [9]. The $29^{\text {th }}$ and $30^{\text {th }}$ consisted of seven levels and each level represents the relevant points. Each item consists of four levels (1-4 points.) each domain consist of raw score and standard score. The raw need to be translated into standard score. Raw score equals to the $\left.\left(\mathrm{Q}_{1}+\mathrm{Q}_{2}+\ldots \mathrm{Q}_{\mathrm{n}}\right) / \mathrm{n}\right)$. Function field: standard score $=(1-($ Raw score -1$) / R) \times 100$; function and overall health: standard score $=(($ raw-1)/R $) \times 100[10]$. The investigation was conducted by trained investigators. Before investigation, we got permission from each interviewee.

\section{Statistical analysis}

We used SPSS13.0 software to finish all analyses. The classification data were expressed as percentage and count. The rate of the two groups was compared by using the chisquare test. For continuous data, the mean \pm standard deviation was used, and t-test was used to compare the difference. The frequency was used to describe the demographic characteristics of patients, and Wilcoxon rank sum test was used. Logistic regression was used to analyse the risk factors of depression in patients with chronic diseases. $\mathrm{P}<0.05$ is of significant difference.

\section{Results}

Four hundred and fifty study subjects were enrolled in the final study, including 171 females and 228 males. The age of study population ranged from 65 to $80 \mathrm{y}$ old, and the mean age was $66.7 \pm 5.6$. The prevalence of depression was $31.8 \%(143 / 450)$. Thirteen cases of severe ( $>72$ points), 40 cases of medium (63-72 points), and 89 cases of mild (53-62 points).

The univariate analysis found that there were no significant difference in depression prevalence between female and male $(\mathrm{P}=0.066)$. No difference was observed in different age group (65-75 vs. $>75)$. People with low educational level tend to have depression, and the prevalence of primary, middle and college and more were $42.7 \%, 27.3 \%$ and $11.8 \%$, respectively $(\mathrm{P}=0.000)$. The prevalence of depression in the urban was lower than that in the rural $(35.9 \%$ vs. $21.6 \%$, there was statistically significance $(\mathrm{P}=0.001)$. People with more number of diseases tend to be depression, the prevalence of depression were $26.0 \%$ for one, $27.9 \%$ for two and $41.4 \%$ for three and more diseases. The burden of disease was related to depression, study subjects with severe burden of disease have higher prevalence of depression than those with light and middle burden of disease $(40 \%, 22.6 \%, 30.0 \%, \mathrm{P}=0.004)$. People who get more social support have lower prevalence of depression compared with those who get little social support. The prevalence of depression was $32.2 \%, 22.0 \%$ and $39.5 \%$ $(\mathrm{P}=0.006)$. These who have free medical costs have lower prevalence and those with self-financed have higher prevalence of depression $(33.3 \%, 43.8 \%, 35.0 \%)$, but no significant difference was observed $(\mathrm{P}=0.325)$. The Table 1 presents the results.

We also assessed the quality of life between depression group and control group. The score of depression group in physical, role, emotion, cognition, social, global health, fatigue, nausea and vomiting, pain, dyspnea, sleeplessness, appetite loss and constipation were higher than that in the control group $(\mathrm{P}=0.000)$, and there were no differences in diarrhea and financial difficulty $(\mathrm{P}=0.064, \mathrm{P}=0.072)$. The results of each function were presented in Table 2.

We also conducted the logistic regression analysis. We treated gender, age, educational level, region, and number of disease, burden of disease, social support, and medical costs as independent variable, and treated depression status as dependent variable (Table 3).

The results indicated that people with more number of diseases have higher risk of depression. Compared with those with one disease, the ORs of people with two and three diseases were 2.67 (95\% CI: 1.24-3.58) and 2.00 (95\% CI: 1.32-2.77). The population with severe burden disease were more likely to be depression compared with those who have light burden of disease $(\mathrm{OR}=2.35,95 \% \mathrm{CI}: 1.39-3.96)$. These with more social support have lower risk of depression. Compared with little social support, the risk of depression for people with many social support decreased by $22 \%$.

Table 1. Relationship between various factors and depression. 
Influence factors of depression in elderly patients with chronic diseases

\begin{tabular}{|c|c|c|c|c|c|}
\hline Factors & Number $(n)$ & Depression (n) & $(\%)$ & $t / x^{2}$ & $\mathbf{P}$ \\
\hline Gender & & & & 3.38 & 0.066 \\
\hline Female & 171 & 70 & 49 & & \\
\hline Male & 228 & 73 & 51 & & \\
\hline Age & & & & 0.61 & 0.435 \\
\hline $65-75$ & 250 & 93 & 65 & & \\
\hline$>75$ & 150 & 50 & 35 & & \\
\hline $\begin{array}{l}\text { Educational } \\
\text { level }\end{array}$ & & & & 30.614 & 0 \\
\hline Primary & 225 & 96 & 67.1 & & \\
\hline Middle & 132 & 36 & 25.2 & & \\
\hline $\begin{array}{l}\text { College and } \\
\text { more }\end{array}$ & 93 & 11 & 7.7 & & \\
\hline Region & & & & 10.823 & 0.001 \\
\hline Rural & 251 & 90 & 55.9 & & \\
\hline Urban & 199 & 43 & 44.1 & & \\
\hline $\begin{array}{l}\text { Number } \\
\text { disease }\end{array}$ & & & & 10.018 & 0.007 \\
\hline
\end{tabular}

\begin{tabular}{llllll}
\hline 1 & 169 & 44 & 30.8 & & \\
\hline 2 & 129 & 36 & 25.2 & & \\
\hline$\geq 3$ & 152 & 63 & 44 & & \\
\hline $\begin{array}{l}\text { Burden } \\
\text { disease }\end{array}$ & of & & & 10.82 & 0.004 \\
\hline Light & 142 & 43 & 30.1 & & \\
\hline Middle & 133 & 30 & 22.6 & & \\
\hline Severe & 175 & 70 & 47.3 & & \\
\hline Social support & & & & 10.185 & 0.006 \\
\hline Light & 157 & 62 & 43.3 & & \\
\hline Middle & 161 & 52 & 36.4 & & \\
\hline High & 132 & 29 & 20.3 & & \\
\hline Medical costs & & 111 & 77.6 & & \\
\hline Part insurance & 317 & 32 & 22.4 & & \\
\hline self-financed & 73 & 20 & 14 & & \\
\hline Free & 60 & & & & \\
\hline
\end{tabular}

Table 2. Effect of depression on the quality of life.

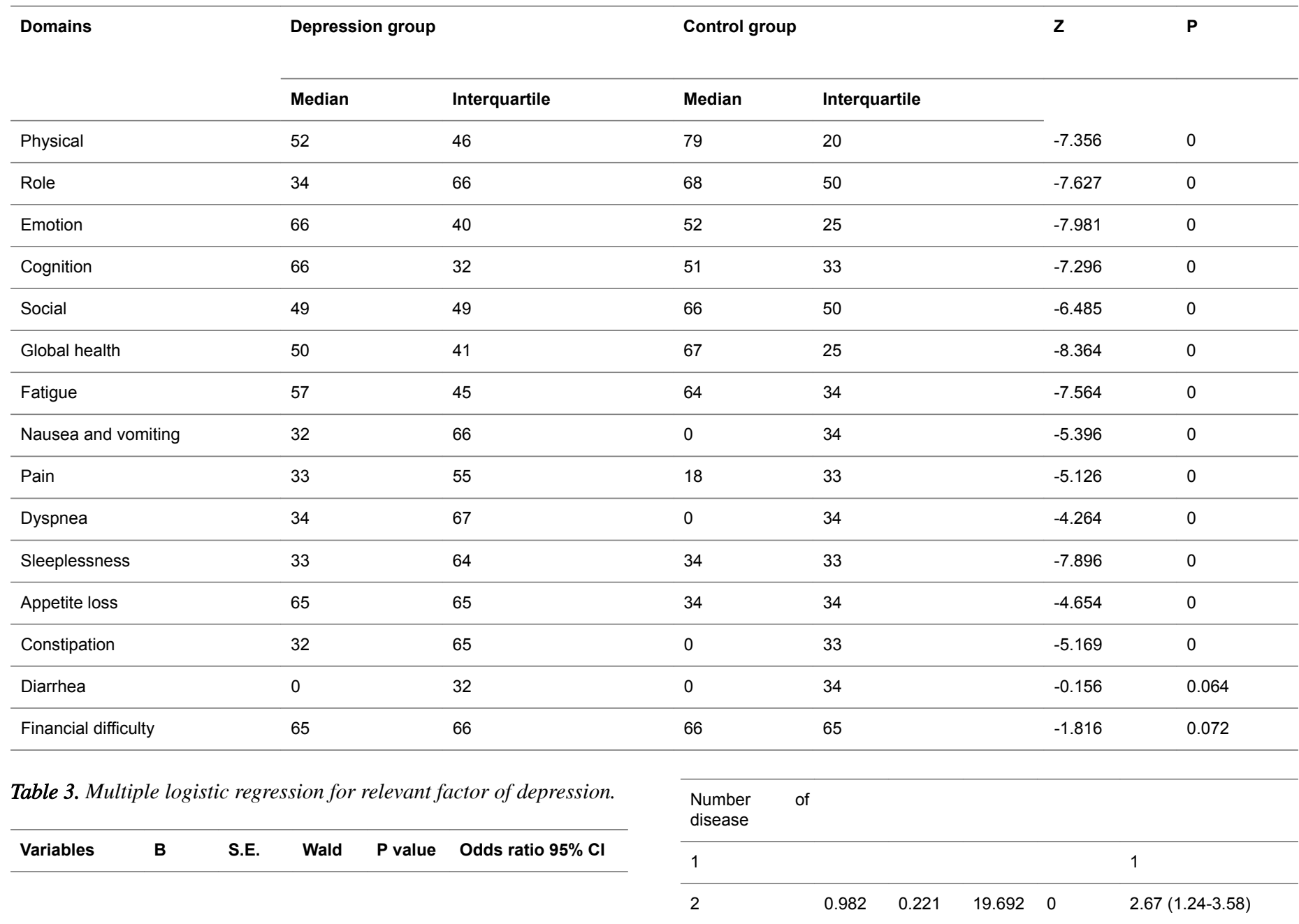




\begin{tabular}{|c|c|c|c|c|c|}
\hline$\geq 3$ & 0.698 & 0.226 & 9.566 & 0.002 & $2.00(1.32-2.77)$ \\
\hline $\begin{array}{l}\text { Burden } \\
\text { disease }\end{array}$ & of & & & & \\
\hline Light & & & & & 1 \\
\hline Middle & 1.2 & 0.253 & 0.503 & 0 & $3.32(2.02-5.45)$ \\
\hline Severe & 0.853 & 0.268 & 10.14 & 0.001 & $2.35(1.39-3.96)$ \\
\hline
\end{tabular}

Social support

\begin{tabular}{llllll}
\hline Little & & & & \multicolumn{2}{c}{1} \\
\hline Middle & 0.164 & 0.195 & 0.646 & 0.256 & $1.18(0.19-4.69)$ \\
\hline Many & 0.521 & 0.176 & 8.803 & 0.003 & $0.68(0.19-0.98)$ \\
\hline
\end{tabular}

\section{Discussion}

Our study found that the occurrence of depression was related to educational level, number of disease, burden of disease, and social support among elderly patients with chronic diseases. Depression affected the quality of life of elderly patients with chronic diseases. The results from multivariate logistic regression suggested that more number of diseases and increased burden of disease and less social support may increase risk of depression in elderly patients with chronic diseases.

Our investigation found that the prevalence of depression in patients with chronic disease was $31.7 \%$. The prevalence was slightly higher than that of previous report in the hypertension cancer. $\mathrm{Li}$ et al. estimated that the prevalence of depression in hypertensive patients was $21.3 \%$ [11], and Watts reported that the prevalence of pretreatment, on-treatment and posttreatment were $25.34 \%$ (CI $22.79 \%$ to $28.07 \%$ ), $22.99 \%$ (CI $19.85 \%$ to $26.46 \%$ ) and $12.71 \%$ (CI $10.14 \%$ to $15.79 \%$ ), respectively [12]. But this prevalence was lower than that in patients with coronary heart disease. The overall prevalence of depression in coronary heart diseases from hospital was 51\% [13]. Depression in patients with chronic diseases was related to many poor health status, consisting of lower quality of life, increased medical costs, not follow the treatment, and even increased mortality $[14,15]$. Our results also found that people with depression usually suffered from the lack of physical and mental function, which is not adverse for patients to recovery. The results indicated that people that with more number of disease have higher risk of depression. The population with severe burden disease were more likely to be depression compared with those who have light burden of disease. These with more social support have lower risk of depression. Compared with little social support, the risk of depression for people with many social support decreased by $22 \%$. These results were in accordance with previous reports $[16,17]$.

Some measures should be taken. To prevent and control the occurrence of depression in the elderly, the government should gradually establish and improve the mental health care services and security system for the elderly which adapted with country's economic and social development, increase financial support to pension services, focusing on socially disadvantaged older age groups, strengthening training and education of rural doctors $[18,19]$; in social dimension: carry out actively various forms of health education, mobilize extensively social activities of respecting and caring the older, creating more sports facilities and activities for the elderly in rural areas; in household level: give full play to the role of spiritual solace of the family, children should not only take the duty to support the elderly in the financial aspects, but should pay attention to the spirit of love; for older people themselves: the elderly should consciously understand the mental health knowledge and actively participate in social activities to strengthen interpersonal and communication, to develop healthy lifestyles to enhance physical and mental health [20]. Some study limitations should be addressed. This study was based on cross-sectional design, and the cause-effect relationship was not so strong. The collected data were from investigation of questionnaires, and some information bias may exist. Besides, the present results were from population with chronic diseases. It should be cautious when applied in other population setting.

In conclusion, the overall incidence of depression disorders for elderly patients with chronic diseases is slightly higher. The clinical staff should pay more attention to the patients of lower education level, poor health care in rural areas and patients with severe burden disease and less social support.

\section{References}

1. Schuz J, Fored M. Chronic disease registries-trends and challenges. Methods Inf Med 2017; 56: 328-329.

2. Godil A, Mallick MSA, Adam AM, Haq A, Khetpal A, Afzal R, Salim M, Shahid N. Prevalence and severity of depression in a pakistani population with at least one major chronic disease. J Clin Diagn Res 2017; 11: 5-10.

3. Jensen E, Dumas BP, Edlund BJ. Depression screening in chronic disease management: a worksite health promotion initiative. Workplace Health Saf 2016; 64: 89-94.

4. Cardin F, Ambrosio F, Amodio P, Minazzato L, Bombonato G, Schiff S, Finotti K, Giuliani D, Bianco T, Terranova C, Militello C, Ori C. Quality of life and depression in a cohort of female patients with chronic disease. BMC Surg 2012; 12: 10.

5. Pelletier R, Bacon SL, Arsenault A, Dupuis J, Laurin C, Blais L, Lavoie KL. Relative associations between depression and anxiety on adverse cardiovascular events: does a history of coronary artery disease matter? A prospective observational study. BMJ Open 2015; 5: 6582.

6. Yang RR, Lu BC, Li T, Du YF, Wang X, Jia YX. The relationship between high-sensitivity C-reactive protein at admission and post stroke depression: a 6-month follow-up study. Int J Geriatr Psychiatry 2016; 31: 231-239.

7. Zahn D, Petrak F, Uhl I, Juckel G, Neubauer H, Hagele AK, Wiltfang J, Herpertz S. New pathways of increased cardiovascular risk in depression: a pilot study on the association of high-sensitivity C-reactive protein with proatherosclerotic markers in patients with depression. J Affect Disord 2013; 146: 420-425. 
8. Kirkby R, Al Saif A, el-din Mohamed G. Validation of an Arabic translation of the Zung Self-Rating Depression Scale. Ann Saudi Med 2005; 25: 205-208.

9. Garratt A, Schmidt L, Mackintosh A, Fitzpatrick R. Quality of life measurement: bibliographic study of patient assessed health outcome measures. BMJ 2002; 324: 1417.

10. Hou ZK, Mi H, Liu FB, Chen ZQ, Chen XL, Wu YH, Che $\mathrm{XL}$. Interpreting the Chinese version of quality of life questionnaire for functional digestive disorders. J Gastroenterol Hepatol 2017.

11. Li Z, Li Y, Chen L, Chen P, Hu Y. Prevalence of depression in patients with hypertension: a systematic review and meta-analysis. Medicine (Baltimore) 2015; 94: 1317.

12. Watts S, Prescott P, Mason J, McLeod N, Lewith G. Depression and anxiety in ovarian cancer: a systematic review and meta-analysis of prevalence rates. BMJ Open 2015; 5: 7618.

13. Ren Y, Yang H, Browning C, Thomas S, Liu M. Prevalence of depression in coronary heart disease in China: a systematic review and meta-analysis. Chin Med J (Engl) 2014; 127: 2991-2998.

14. Arnow BA, Blasey CM, Lee J, Fireman B, Hunkeler EM, Dea R, Robinson R, Hayward C. Relationships among depression, chronic pain, chronic disabling pain, and medical costs. Psychiatr Serv 2009; 60: 344-350.

15. Gilman SE, Sucha E, Kingsbury M, Horton NJ, Murphy JM, Colman I. Depression and mortality in a longitudinal study: 1952-2011. CMAJ 2017; 189: 1304-1310.

16. Gonzalez-Saenz DTM, Bilbao A, Bare M, Briones E, Sarasqueta C, Quintana JM, Escobar A. Association between social support, functional status, and change in health-related quality of life and changes in anxiety and depression in colorectal cancer patients. Psychooncology 2017; 26: 1263-1269.

17. Cheong EV, Sinnott C, Dahly D, Kearney PM. Adverse childhood experiences (ACEs) and later-life depression: perceived social support as a potential protective factor. BMJ Open 2017; 7: 13228.

18. Agrawal N, Bird JS, von Oertzen TJ, Cock H, Mitchell AJ, Mula M. Depression correlates with quality of life in people with epilepsy independent of the measures used. Epilepsy Behav 2016; 62: 246-250.

19. Kim KN, Lee MR, Choi YH, Lee BE, Hong YC. Associations of blood cadmium levels with depression and lower handgrip strength in a community-dwelling elderly population: a repeated-measures panel study. J Gerontol A Biol Sci Med Sci 2016; 71: 1525-1530.

20. Min J, Ailshire J, Crimmins EM. Social engagement and depressive symptoms: do baseline depression status and type of social activities make a difference? Age Ageing 2016; 45: 838-843.

\section{*Correspondence to}

Weijia Sun

Department of General Surgery

Xiangya Hospital

Central South University

PR China 